Population biobanks and returning individual research results - mission impossible or new directions?

Susan E. Wallace, Ph.D. (corresponding author)

Lecturer in Population and Public Health Sciences

University of Leicester

Department of Health Sciences

212a Adrian Building, University Road

Leicester, UK LE1 7RH

Work: $+44(0) 1162997259$

Fax: $+44(0) 1162997250$

Home: $+44(0) 1162700456$

Mobile: +44 (0)770 8961741

Email: sew40@le.ac.uk (preferred contact method)

\title{
Alastair Kent
}

Director

Genetic Alliance UK

Unit 4D, Leroy House

436 Essex Road

London, UK N1 3QP

Work: +44 (0) 2077043141

Fax: +44 2073591447

Email:alastair@geneticalliance.org.uk

\section{$\underline{\text { Abstract }}$}

Historically, large-scale longitudinal genomic research studies have not returned individual research results to their participants, as these studies are not intended to find clinically significant information for individuals, but to produce 'generalisable' knowledge for future research. However, this stance is now changing. Commentators now argue that there is an ethical imperative to return clinically significant results and individuals are now expressing a desire to have them. This shift reflects societal changes, such as the rise of social networking and an increased desire to participate in medical decision-making, as well as a greater awareness of genetic information and the increasing ability of clinicians to use this information in healthcare treatment. This paper will discuss the changes that have prompted genomic research studies to reconsider their position and presents examples of projects that are actively engaged in returning individual research results.

Keywords: genomics, human population genetics, genetic databases, genome research, ethics of human genetics, social issues 


\section{Introduction}

There has been considerable discussion regarding returning individual research results to participants in genomic research studies. The debates have focused on what constitutes a 'result', when should such findings be communicated, who has the ethical duty to disclose findings, and for which kinds of research study should they be disclosed. With large-scale longitudinal genomic research studies, data and samples are collected in a repository for use in future research studies. In this context, the policy has been that individual results would not be returned, either on grounds of cost or uncertainty regarding the value of the results in a clinical setting pending further verification. However, this stance is now changing. In this article, we present the historic position taken by population biobanks, the new drivers that are pushing projects to either review their policies or build in procedures to deal with this issue, and examples of how some biobanks are moving forward in response.

\section{Historic position}

Population biobanks have traditionally provided two kinds of 'results' to participants. The first are the results from the assessment that individuals undergo as part of joining the study. Individuals are usually given a series of tests and measurements, in addition to, in some cases, being asked to complete health and lifestyle questionnaires. Results from these initial assessments (e.g. blood pressure, BMI, and weight) can be given to the participant, at the end of their induction session, often in the form of a written summary. If during this preliminary session an assessment level is considered unsafe, biobank staff will direct the person to speak about the result to their general practitioner or, if necessary, urge them to go immediately to a hospital or clinic to have the problem investigated (Knoppers and Kharaboyan 2009). Many potential participants see these initial assessment results as an incentive to join the biobank. Godard et al found that for participants in the CARTaGENE biobank, "[ $\mathrm{t}]$ he most important criteria for participating in the...project would be the possibility of obtaining the results of the biochemical test performed at the time of the interview" (Godard et al. 2007). Secondly, once the biobank's resources have been used by outside researchers, general results from these studies are provided to participants and others, through various media such as on the biobank's website, or as newsletters and leaflets that might be made available through medical professionals or through the post to participants. This reflects the ethical imperative 
to publish, as well as a way to show respect for and acknowledge the efforts of study participants.

On the other hand, it has been suggested that individual level research results, and particularly genetic information, not be fed back to participants (Beskow et al. 2001) and this has been reflected in the consent materials of biobanks (Wallace et al. 2009). There are several arguments for this. Population biobank studies are not intended to find clinically significant information for individuals, but to produce 'generalisable' knowledge for future research and therefore it could be argued that there is no case for returning results to individuals. As biobanks are designed as resources for future research, there is also the difficulty of securing adequate consent from participants with regard to as yet undiscovered outcomes, some of which might be highly significant (for example a mutation in a dominant gene for an unsuspected late onset disorder) while others may be of more limited value, such as a slightly raised predisposition to a common disorder (Caulfield et al. 2003).

Commentators also have argued that the depth of the relationship between the researcher and the participant should be a factor in the feeding back of results (Ravitsky and Wilfond 2006; Beskow and Burke 2010; NHGRI Intramural Research Bioethics Core 2010). When considering obligations such as returning results, “...researchers have a stronger moral responsibility to engage with a fuller range of participants' needs when the relationship is deeper" (Beskow and Burke 2010). Conversely, when the relationship is more distant, this can mitigate the need to return results. This certainly could apply in the case of a healthy volunteer's data in a population biobank being used by a 'secondary researcher,' defined as those researchers who are not involved in the original project but are "... accessing the data through managed data access mechanisms"(UK10K 2010) The relationship between a secondary researcher and a participant can be seen to be physically distant, if the research is taking place in another institution perhaps in another country; furthermore, the secondary research may take place long in the future, creating a gap between the time of joining the biobank and the time of the discovery.

A balance must also be struck between using resources to further the research and the costs associated with maintaining the option of re-contact with individual participants in the event of a significant discovery emerging. Biobanks are expensive enterprises (Elliott and Peakman 2008) and some have argued that it is a mistake to stray from the goal of knowledge for the 
public good to that of benefiting individuals (Forsberg et al. 2009). Also, with early outcomes of uncertain value, initial findings need to be confirmed by further research to avoid premature conclusions and prevent unnecessary alarm and invasive follow-up testing. Concern about the use of associations between observed changes in the genome and predictions about the consequent risks of common disease by companies selling genetic tests direct to the public has been raised by the UK Human Genetics Commission, resulting in the production of a code of conduct (Human Genetics Commission 2010) and by the US Secretary's Advisory Committee on Genetics, Health and Society (Secretary's Advisory Committee on Genetics Health and Society 2010). In addition, California and New York, have ordered direct-to-consumer genetic testing companies to stop soliciting business from state residents (Langreth and Herper 2008; Pollack 2008). The 'downstream' work to validate suspected findings has not been within the remit of the population studies themselves, but that of the researchers accessing the resource.

Commentators are also considering whether agreeing to return results might impose fiduciary duties on biobank administrators (Morreim 2005; Meltzer 2006). Therapeutic misconception (Appelbaum et al. 1982) is another concern. Studies have shown that, in the context of clinical trials, research participants do not always appreciate and understand the important differences between research and treatment (Henderson et al. 2007). If clinically-relevant results are given to them this may enhance any confusion.

However, many commentators now consider this position of not returning individuals results as untenable. Based on arguments of autonomy (Rothstein 2006) and the rejection of paternalism on the part of researchers (Fernandez 2008), they argue that participants should be able to access their results. Moreover, the desire of individuals to receive their results when participating in research studies appears to be on the rise (Murphy et al. 2008; Meulenkamp et al. 2010). The factors driving this change in attitude are varied, however clues may be found in the parallel progression of changes in society, together with the increase of genetics knowledge, as a result of the completion of the Human Genome Project (HGP). These changes are forcing population biobanks to reconsider their stance on returning results.

\section{New drivers}


The first drafts of the human genome sequence were published in 2001 (International Human Genome Sequencing Consortium 2001); (Venter et al. 2001) and the 'finished' sequence (>99\% completion and accuracy of $>99.999 \%$ (Lander 2011)) in 2004 (International Human Genome Sequencing Consortium 2004). The improvements in sequencing technology have been monumental. While the HGP used essentially the same techniques introduced by Fred Sanger in 1977, since its completion,

[t] he per-base cost of DNA sequencing has plummeted by $\sim 100,000$-fold over the past decade, far outpacing Moore's law of technological advance in the semiconductor industry. The current generation of [sequencing] machines can read 250 billion bases in a week, compared to 25,000 in 1990 and 5 million in 2000 (Lander 2011).

The ability to sequence a large number of base pairs at a relatively low cost is one of the drivers behind 'personalised medicine' (the ability to determine the right medicine for the right person at the right time) and 'personal genomics' ("the sequencing of an individual's genome for health-related enquiry or for determining genetic predisposition to disease" (Mardis 2011)). Individuals such as James Watson, co-discoverer of the chemical structure of DNA have had their genomes completely sequenced (Wheeler et al. 2008), and the ability to sequence a person's genome raises the question of what to do with that information and how to communicate it (McGuire and Lupski 2010). Whole genome sequencing produces an enormous amount of data about an individual; at this point in time, much of it cannot be interpreted. However, the evidence base is growing and clinical applications are becoming more readily available.

Personal genomics companies now provide customers with a genotype profile based on a selected number of single nucleotide polymorphisms (SNPs) that indicate a potential predisposition towards conditions and tendencies. For example, 23 andMe will provide genetic analysis information on personal traits, cancer status, drug response and disease risk (23andMe 2011). While commentators debate the efficacy and worthiness of such personal genomic profiles (Magnus et al. 2009; Samuel et al. 2010), 23andMe believes they are "...democratizing personal genetics and expanding the opportunity for more people to benefit from the genetic revolution" (23andMe 2008). Claims of the predictive power of these DNAbased diagnostics may now be contributing to a climate of expectation about the utility of biobank-derived information. Thus private practice (whether good or bad) appears to be driving public policy. 
This desire for one's personal genome is one reflection of societal shifts over the last few decades. On one hand, genetics and genomics knowledge is increasing and becoming part of everyday language as well as more and more significant in medical practice. In parallel, society has been changing from a position where a paternalistic view of life was accepted to one where people are taking greater individual control in their day-to-day lives. The rise of personal computing and social networking has changed the way in which individuals live their lives. Internet use has increased dramatically over the last decade and internet-based social networks, such as Facebook and Twitter, are now used extensively for casual as well as business uses. They are also used extensively as a part of social activism, as shown in the early-2011 uprisings in Egypt (Alexander 2011). In medicine, patient activists are becoming more and more a part of the health care and drug development process; patient-driven medicine (or participatory medicine) is on the rise (Frydman 2009). Patient groups in online communities are sharing their experiences with each other and clinicians through social media sites.

...[P]atients suffering from a variety of diseases and chronic conditions are overcoming what formerly was a stigma of discussing with others the progression of their illnesses and how they respond to different treatments. "People are realizing more and more the incredible value of sharing medical information," [Benjamin Heywood, President of Patients Like Me] said (Weisman 2011).

With an increased knowledge of genetics, together with the growing ability to personally control one's environment, and the ability to contribute directly to the progress of medicine research, it is not surprising that people are actively seeking personal health data. This includes participants in large scale population biobank studies.

\section{$\underline{\text { 4. Public perceptions about the application of genetics in non clinical contexts }}$}

Although biobanks are established for the purposes of facilitating research by others into the genetic components of health and disease, and because of this they generally benefit from high levels of public support and legitimation, this cannot be taken for granted by those responsible for their establishment and future maintenance. The application of genetics in non-medical contexts is also on the increase, and this inevitably colours the perceptions of citizens, policy makers and regulators as to the potential risks and benefits associated with this technology. 
The depiction of forensic science on television, the use of forensic databases for the detection of crime, and the rise in DNA-based paternity testing have created a perception of certainty about the dependability of genetic information. The 'CSI Effect,' defined as “...the phenomenon in which jurors hold unrealistic expectations of forensic evidence and investigation techniques" (Robbers 2008) has been demonstrated to be real and is influencing not only jurors but the way in which judges and law enforcement officials act as well (Durnal 2010). In the UK, public consultations do not focus on whether or not there should be a UK DNA Database, but rather how it should be constituted, used and governed (Human Genetics Commission 2009). The American Association of Blood Banks reported that relationship testing in its accredited laboratories has risen steadily from 1988 with 77,000 reported cases, to almost 415,000 cases in 2008 (AABB 2008).

Recreational uses, such as ancestry tracing, are also growing in popularity. The success of television shows such as 'Who Do You Think You Are?' have encouraged people to seek out their ancestors; many websites now exist that will provide information on your ethnic origins for a fee, although there is some dispute whether these services are accurate (Goffe 2009). Genealogical tourism to trace one's family history is a growing business, with people taking trips to visit ancestral lands, as well as to visit genealogical libraries for research purposes (Santos and Yan 2010). Santos and Yan postulate that "...by fashioning group distinctiveness and drawing on ancestry, one is able to rescue one's individuality," a commodity that is being eroded in modern society (Santos and Yan 2010). This sense of individuality goes one step further with the introduction of genetic testing. Vendors are now providing the DNA test, the subsequent ancestral data analysis and the appropriate travel arrangements to visit the land of one's ancestors in one complete package (Naish 2010).

The search for one's genetic roots can have unsuspected and sometimes unwelcome ramifications. The consequences of the revelation that one's biological father is not the same as one's social father can be devastating for a family (with the risks of discovering unexpected "discontinuities" in ones lineage either ignored or even made light of - a recent UK TV advertisement for one of these services introduced the milkman as an ancestor) (Genes Reunited 2010). As well, there is continued speculation about the potential for insurers to use genetic information to exclude people at risk from cover (Joly et al. 2010). This has led to restrictions on access by insurers based on either voluntary codes such as the concordat and moratorium between the UK Government and the Association of British 
Insurers (HM Government and Association of British Insurers 2005), recently extended until 2017 (Association of British Insurers 2011), or on statutory prohibition such as the Genetic Information Non-Discrimination (GINA) Act in the US (GINA 2008). Despite these measures, suspicion of insurers' intentions remains widespread and this is reflected in often inconsistent attitudes to the use of genetic information by public and private bodies on the part of individuals and groups.

\section{$\underline{\text { 5. Guidance for returning results }}$}

Outside of population biobanks, many organisations have considered the implications and processes related to returning individual research results, especially genetic results (Knoppers et al. 2006; Dressler 2009; NHGRI Intramural Research Bioethics Core 2010). As far as the process is concerned, it is recommended that researchers "... should have a clearly articulated policy on feedback and the nature of the feedback, if any, that will be provided to participants" (OECD 2009). Common, if not unanimous, agreement can be found on the conditions and processes that might make up this policy:

- The IRB, the researcher, and other appropriate experts are responsible to make the determination about disclosure.

- Research subjects need to be given an opportunity to decide whether they want to receive the research results.

- Informed consent process and document should indicate if disclosure is planned or likely and describe the risks associated with disclosure.

- Only professionals capable of providing genetic counseling should give genetic or genomic research results.

- Counseling of patients before and after receiving research result is required.

- Oversight of the disclosure process is required. (Dressler 2009)

If there is an agreed plan for disclosure, it needs to be approved by an ethics review board and made clear to potential participants. In addition, any results should be determined to be analytically and clinically valid. Some commentators believe that there should also be some form of medical intervention to offer the individual; others believe that this is not a requirement, especially when there are no known or no effective interventions (Dressler 2009). Regardless, the participant needs to have been told whether there is a possibility of results being returned and asked for their consent. If they decide they do not wish to know, this should be respected. If the decision is taken to not return results to individuals, this too must be made clear to potential participants. 


\section{Examples from biobanks and other large-scale genetic research studies}

These guidelines are of general use to a population biobank, however they are not completely appropriate, as they do not fit with the structure and mission of a biobank and thus create potential difficulties. As mentioned, biobanks are not designed to be concerned with the healthcare needs of individuals and will generally not have the resources, such as the services of genetic counsellors, available to them. But if they wish to address this issue, population biobanks need to consider how to include the potential for immediate individual benefit into the structure of a population-based resource being created for future unknown research. With no specific guidance to draw from, population biobanks are looking at old and new practices, being used by other biobanks and longitudinal studies, from which they can tailor their own policies.

\section{a. Returning results through a general practitioner}

LifeLines, hosted by the University of Groningen, Netherlands, is "a cohort study to investigate universal risk factors and their modifiers for multifactorial diseases" (Stolk et al. 2008). Participants are recruited, for the most part, through their general practitioner (GP) and it is through this relationship that the results process is managed. The LifeLines researchers worked with the recruiting GPs to define cutoff levels for assessment information (e.g. blood pressure and serum glucose results). If one of these assessment levels causes concern, the participant will receive a letter telling them that they should contact their GP to discuss it, while their GP receives a letter with the actual results. Specific genetic information is not returned so that the individual can say that they have not had genetic testing, as this has implications related to insurance. If LifeLines researchers discover validated and clinically significant information that will have an influence on a participant's health, it is reported to their GP, who will then discuss it with them.

This model provides a bridge between the biobank and the participant recruited through the GP and relies on the strength of the GP-patient relationship that exists in many parts of the world to provide an avenue for returning of results. It would certainly seem logical that primary care settings, where the relationship between the GP and individual is clear and may be long-standing, would be the appropriate setting for receiving and discussing clinically significant, and perhaps life-altering, health information. However, this depends on the 
healthcare system having an emphasis on continuity between a GP and a patient, a situation that might not exist in all countries.

b. Returning results directly to individuals after consideration by an oversight committee Researchers look to their ethics review board for assistance in deciding how to handle questions of ethical conduct in research. However, these boards are responsible for approving, and in some cases monitoring, hundreds of research projects. They may not have the time or expertise to deal with the specifics of returning results in one specific study, especially if that is a large-scale population-based study with thousands of participants. Therefore, some projects create internal committees, similar to data monitoring or data access committees that work together with the executive committee of the biobank and the responsible ethics review bodies. Kohane and colleagues (Kohane et al. 2007) have suggested the model of an Informed Cohort Oversight Body (ICOB), an independent body responsible for returning results to participants. This body would be composed of various experts, including ethicists, geneticists, and patients, who would make decisions regarding which results would be returned and how it would be done. This model is now being put into practice.

The Coriell Personalized Medicine Collaboration (CPMC) is “....an evidence-based research study designed to determine the utility of using personal genome information in health management and clinical decision-making" (CPMC 2011). It is not a population biobank, but a longitudinal study using the ICOB model to oversee the return of results. The study aims to recruit 100,000 adults (over age 18) from in and around the Delaware Valley, in the northeastern part of the US. Study researchers are investigating the impact of personalised genetic information on people's health and whether it can indeed be used to improve outcomes. With consent, saliva is collected from volunteers. An online account is created for each participant where that person completes health questionnaires. The saliva sample is genotyped to determine genetic variations and a personalised genetic report is made available online to the participant. This report will contain risk information on various conditions, as well as how the individual may react to certain medications (named drug-gene pairs by CPMC). Participants are then able to discuss their reports with their GP, family member or a genetic counsellor and make healthcare decisions accordingly. They can also allow secondary researchers access to their coded data. The CPMC has formed an ICOB to review the state-of-the-science; only those drug-gene pairs and genetic variants for health conditions approved by the ICOB will 
be given out. Their criteria for approving which conditions and gene variants it will return are the association between the variation and the condition and the actionability of the variant and the interventions available. Approved conditions include age-related macular degeneration, coronary heart disease and melanoma. Study researchers will follow participants over the course of a minimum of five years, asking for updated medical information and how they have used their personal genetic information.

A consortium of biobanks is also using an oversight committee in its work, also related to electronic medical records. The eMERGE (Electronic Medical Records and Genomics) network is a US-based, “...national consortium formed to develop, disseminate, and apply approaches to research that combine DNA biorepositories with electronic medical record (EMR) systems for large-scale, high-throughput genetic research” (eMERGE Network 2011). eMERGE brings together five projects, each of which "...study the relationship between genome-wide genetic variation and a common disease/trait" (McCarty et al. 2011). As part of their study, they have established several working groups, one of which is the Return of Results Oversight Committee. As this committee is new and has not as yet published policies, the processes it will choose to suggest to its member biorepositories are unknown at this time. However, rather than not return results as it had done in the past, its proposed informed consent language clearly states that contact may be made with participants:

"You should not expect to get individual results from research done through the Biobank. Researchers must study samples and information from many people over many years before they can know if the results have meaning. We will not give the results to your doctor. We will not put them in your medical record. There is a small chance that researchers could discover something that might be very important to your health or medical care right now. If this happens, we will contact you to see if you want to learn more" (eMeRGE Network 2009)

\section{c. Returning all information to participants}

The previous two models reflect the position that healthcare and other related professionals are necessary to act as gatekeepers between the science and the individual and make decisions as to what information that individual should receive. The Personal Genome Project (PGP) takes an alternative position on this subject. While not strictly a large-scale population biobank, this cohort study is recruiting participants “...to contribute genomic sequence data, tissues, and extensive environmental, trait, and other information to a publicly accessible and identifiable research database" (Lunshof et al. 2010). Their aim is to enroll 100,000 participants who will openly share their genomic and health-related information, as well as 
their experiences as a participant. PGP researchers give participants a Preliminary Research Report that includes the genetic variants that have some likelihood of clinical relevance and instructs them to confirm anything potentially significant with their GP or care provider. In this process the intermediary is removed and the participant has control of the information, although there is still an acknowledgement that a health professional is necessary for interpreting the data. However, when it comes to the work of secondary researchers, the PGP states in its consent form that:

Generally, the PGP will not provide you with the results of any analysis, development or other work performed by third parties with access to your tissues or cell lines. However, because such results may be made publicly available, and may be identified as deriving from your tissues or cell lines, you may become aware, even without your consent, of the results of such activities (PGP 2011)

Therefore, the PGP can be seen as akin to the traditional biobank in that it gives its members results of an assessment (albeit a much more extensive one), but does not return results from secondary researchers.

\section{d. Returning no results}

Longitudinal biobanks that have been recruiting for several years according to an agreed epidemiological strategy and consent procedures may decide not to, or may not be able to, change their long standing position regarding returning results. For example, UK Biobank, which completed its recruitment of 500,000 participants in late 2010, has had a 'no-returns' policy since its beginning. It states on its website that while individuals will be given results from the assessment if they choose, they will not receive results from future research:

"1.What will I get out of attending an appointment?

You will be helping in a research study aimed at improving the health of future generations. We will at the end of the visit give you a report of the results of some of the measurement undertaken - this will include your blood pressure, lung function, body mass index, $\%$ body fat, weight and height.

2.Will you tell me if you find something wrong with me?

We will tell you if your blood pressure is particularly high or low or if your lung function is significantly reduced.

During the next 20-30 years, samples will gradually be analysed as the Biobank resource becomes available for medical research of all kinds, both in Britain and around the world. As this may be far in the future, and researchers will be analysing anonymised samples, we will be unable to inform you of any findings." (UK Biobank 2011)

Whether this policy will change in the future for this or any other long-standing biobank is unknown. If a biobank does choose to revise its policy and address return of results, it will need to consider whether original consent materials allow for re-contact of participants. Re- 
contact is one provision longitudinal biobanks typically include in their consent materials (Cambon-Thomsen et al. 2007), as this allows the biobank to ask participants for additional data from health records or if they wish to participate in specific research studies.

\section{The future for population biobanks}

This is a new issue for population biobanks and few details have been published. This paper has used examples from other large-scale longitudinal studies, as well as biobanks, to show how study organisers are beginning to integrate returning results into their practice. Some studies are creating committees to consider queries from researchers who may be wondering whether certain information should be returned to a biobank participant. Oversight boards are being used to assist researchers in decisions regarding which variant information should be given to participants. However, the evidence is limited at this stage and biobanks need to carefully plan how they will deal with this issue and have any procedures reviewed and approved by their ethics review board. Consent materials should make clear whether any results will be returned to participants and if so, how it will be done. Re-contact measures will need to be discussed. Regardless, returning results should not be used as an incentive to join a study, as this is inconsistent with the nature of these kinds of studies (Knoppers and Laberge 2009) and it may introduce confusion amongst participants (e.g., joining for potential medical benefit rather than as an altruistic act to support research for the benefit of future generations.)

Biobank administrators must be aware that even the 'best laid plans' need some flexibility. Time should be dedicated to anticipating future contingencies; long-term population studies will necessarily not produce results in the short term but one cannot know when a discovery will be made that will impact the lives and health of individuals. In addition, anecdotal evidence has shown that participants may demand results even if the policy of the project was not to disclose them, especially if researchers find a mutation that might respond to a therapy or develop an intervention that might be beneficial. Researchers agree that there is a moral imperative to return results that may significantly impact an individual's life; how this will be done needs careful consideration.

\section{$\underline{\text { Conclusions }}$}


Historical policies regarding the issue of whether or not results should be returned to research subjects by biobanks or by the researchers using biobank samples and data have been deliberately cautious. In part, this has been due to justifiable concerns regarding the validity and the significance of such results and the need for further validation before they can be used as a basis for action by research participants and/or clinicians. In part this has been for ethical concerns about the release of information to individuals who have not asked for it and may not want it, and in part it has been for practical reasons arising from the cost and the logistical difficulty of organising an appropriate procedure.

These assumptions are increasingly being challenged. Public perceptions regarding ownership of genetic information - "It's my genome and I am entitled to have the information in it" - and professional anxieties about the ability of sample donors to handle complex information of uncertain value are shifting. Novel communication possibilities are opening up cost effective ways of disseminating information to individuals, groups or populations. Advances in genetics and genomics are increasing the probability of unanticipated information being revealed (some are talking of the $\$ 100$ genome being a reality in the foreseeable future), and practices in the private sector regarding genetic predisposition testing are influencing public expectations with regard to the outputs from public sector biobanks.

It is clear that the historical dam, behind which the flow of genetic and genomic data was held until it could be released in a carefully controlled manner to a few licensed recipients, will come under increasing pressure and may well prove to be unsustainable - even if society deems it desirable to do so. Policies for the return of findings to research participants must be subjected to regular review and where appropriate and necessary, amended to reflect changing circumstances and possibilities. In so doing, researchers can consistently demonstrate fitness for purpose, securing public trust in the operation of biobanks, and hence contribute to the sustainability of these valuable yet expensive resources.

\section{$\underline{\text { References }}$}

23andMe (2008) 23andMe Democratizes Personal Genetics. https://www.23andme.com/about/press/20080909b/. Accessed 15 February 2011 23 andMe (2011) Health reports: complete list. https://www.23andme.com/health/all/. Accessed 20 April 2011 
AABB (2008) American Association of Blood Banks Annual Report Summary for Testing in 2008. http://www.aabb.org/sa/facilities/Documents/rtannrpt08.pdf.

Alexander A (2011) Internet role in Egypt's protests. BBC News. http://www.bbc.co.uk/news/worldmiddle-east-12400319. Accessed 7 March 2011

Appelbaum PS, Roth LH, Lidz C (1982) The therapeutic misconception: Informed consent in psychiatric research. International Journal of Law and Psychiatry 5 (3-4):319-329. doi:10.1016/0160-2527(82)90026-7

Association of British Insurers (2011) Insurance Genetics Moratorium extended to 2017 http://www.abi.org.uk/Media/Releases/2011/04/Insurance_Genetics_Moratorium_extended_t o_2017.aspx. Accessed 20 April 2011

Beskow LM, Burke W (2010) Offering individual genetic research results: context matters. Science Translational Medicine 2 (38):1-5

Beskow LM, Burke W, Merz JF, Barr PA, Terry S, Penchaszadeh VB, Gostin LO, Gwinn M, Khoury MJ (2001) Informed consent for population-based research involving genetics. JAMA 286 (18):2315-2321

Cambon-Thomsen A, Rial-Sebbag E, Knoppers BM (2007) Trends in ethical and legal frameworks for the use of human biobanks. Eur Respir J 30 (2):373-382

Caulfield T, Upshur RE, Daar A (2003) DNA databanks and consent: A suggested policy option involving an authorization model. BMC medical ethics 4 (1). doi: 10.1186/1472-6939-4-1

CPMC (2011) Coriell Personalized Medicine Collaborative. http://cpmc.coriell.org/. Accessed 20 April 2011

Dressler LG (2009) Disclosure of Research Results from Cancer Genomic Studies: State of the Science. Clinical Cancer Research 15 (13):4270-4276. doi:10.1158/1078-0432.ccr-08-3067, p 4274

Durnal EW (2010) Crime scene investigation (as seen on TV). Forensic Science International 199 (13):1-5. doi:10.1016/j.forsciint.2010.02.015

Elliott P, Peakman TC (2008) The UK Biobank sample handling and storage protocol for the collection, processing and archiving of human blood and urine. International Journal of Epidemiology 37 (2):234-244. doi:10.1093/ije/dym276

eMeRGE Network (2009) Model Consent Language. https://www.mc.vanderbilt.edu/victr/dcc/projects/acc/images/7/7e/EMERGEModelLanguage 2009-12-15.pdf. Accessed 20 April 2011

eMERGE Network (2011) The eMERGE Network: Electronic Medical Records \& Genomics. https://www.mc.vanderbilt.edu/victr/dcc/projects/acc/index.php/Main_Page. Accessed 19 April 2011

Fernandez C (2008) Public expectations for return of results - Time to stop being paternalistic? The American Journal of Bioethics 8 (11):46 - 48

Forsberg JS, Hansson MG, Eriksson S (2009) Changing perspectives in biobank research: from individual rights to concerns about public health regarding the return of results. Eur J Hum Genet 17 (12):1544-1549

Frydman G (2009) Patient-driven research: Rich opportunities and real risks. J Participat Med 1 (1):e12

Genes Reunited (2010) NEW Genes Reunited TV Ad. http://www.genesreunited.co.uk/media/?vk=395. Accessed 7 March 2011

GINA (2008) Genetic Information Nondiscrimination Act of 2008, Public Law 110 - 233122 Stat. 881 (May 21)

Godard B, Marshall J, Laberge C (2007) Community Engagement in Genetic Research: Results of the First Public Consultation for the Quebec CARTaGENE Project. Community genetics 10 (3): $147-158$

Goffe L (2009) Americans Seek Their African Roots. BBC News. http://news.bbc.co.uk/1/hi/world/africa/8117258.stm. Accessed 20 April 2011

Henderson GE, Churchill LR, Davis AM, Easter MM, Grady C, Joffe S, Kass N, King NMP, Lidz CW, Miller FG, Nelson DK, Peppercorn J, Rothschild BB, Sankar P, Wilfond BS, Zimmer CR (2007) Clinical Trials and Medical Care: Defining the Therapeutic Misconception. PLoS Med 4 (11):e324 
HM Government and Association of British Insurers (2005) Concordat and Moratorium on Genetics and Insurance.

http://www.dh.gov.uk/prod_consum_dh/groups/dh_digitalassets/@dh/@en/documents/digital asset/dh_4106050.pdf. Accessed 12 April 2011

Human Genetics Commission (2009) Nothing to hide, nothing to fear? Balancing individual rights and the public interest in the governance and use of the National DNA Database.

http://www.hgc.gov.uk/UploadDocs/DocPub/Document/Nothing\%20to\%20hide,\%20nothing \%20to\%20fear\%20-\%20online\%20version.pdf. Accessed 12 April 2011

Human Genetics Commission (2010) A Common Framework of Principles for Direct-to-Consumer Genetic Testing Services.

http://www.hgc.gov.uk/UploadDocs/DocPub/Document/HGC\%20Principles\%20for\%20DTC \%20genetic\%20tests\%20-\%20final.pdf. Accessed 4 March 2011

International Human Genome Sequencing Consortium (2001) Initial sequencing and analysis of the human genome. Nature 409 (6822):860-921. doi:http://www.nature.com/nature/journal/v409/n6822/suppinfo/409860a0 S1.html

International Human Genome Sequencing Consortium (2004) Finishing the euchromatic sequence of the human genome. Nature 431 (7011):931-945. doi:http://www.nature.com/nature/journal/v431/n7011/suppinfo/nature03001_S1.html

Joly Y, Braker M, Le Huynh M (2010) Genetic discrimination in private insurance: global perspectives. New genetics and society 29 (4):351 - 368

Knoppers BM, Joly Y, Simard J, Durocher F (2006) The emergence of an ethical duty to disclose genetic research results: international perspectives. Eur J Hum Genet 14 (12):1322-1322

Knoppers BM, Kharaboyan L (2009) "Deconstructing" Biobank Communication of Results. SCRIPTed 6(3):677-684.

Knoppers BM, Laberge C (2009) Return of "Accurate" and "Actionable" Results: Yes! The American Journal of Bioethics 9 (6):107 - 109

Kohane IS, Mandl KD, Taylor PL, Holm IA, Nigrin DJ, Kunkel LM (2007) Reestablishing the Researcher-Patient Compact. Science 316 (5826):836-837. doi:10.1126/science.1135489

Lander ES (2011) Initial impact of the sequencing of the human genome. Nature 470 (7333):187-197. doi:http://www.nature.com/nature/journal/v470/n7333/abs/10.1038-nature09792unlocked.html\#supplementary-information

Langreth R, Herper M (2008) States Crack Down On Online Gene Tests. Forbes.com. http://www.forbes.com/2008/04/17/genes-regulation-testing-biz-cx_mh_bl_0418genes.html. Accessed 4 March 2011

Lunshof JE, Bobe J, Aach J, Angrist M, Thakuria JV, Vorhaus DB, Hoehe MR, Church GM (2010) Personal genomes in progress: from the Human Genome Project to the Personal Genome Project. Dialogues in Clinical Neuroscience 12 (1):47-60

Magnus D, Cho MK, Cook-Deegan R (2009) Direct-to-consumer genetic tests: beyond medical regulation? Genome Medicine 1 (2):17

Mardis ER (2011) A decade/'s perspective on DNA sequencing technology. Nature 470 (7333):198203

McCarty C, Chisholm R, Chute C, Kullo I, Jarvik G, Larson E, Li R, Masys D, Ritchie M, Roden D, Struewing J, Wolf W, The eMERGE Team (2011) The eMERGE Network: A consortium of biorepositories linked to electronic medical records data for conducting genomic studies. BMC Medical Genomics 4 (1):13

McGuire AL, Lupski JR (2010) Personal genome research : what should the participant be told? Trends in Genetics 26 (5):199-201. doi:10.1016/j.tig.2009.12.007

Meltzer LA (2006) Undesirable Implications of Disclosing Individual Genetic Results to Research Participants. The American Journal of Bioethics 6 (6):28 - 30

Meulenkamp TM, Gevers SK, Bovenberg JA, Koppelman GH, Vlieg AvH, Smets EMA (2010) Communication of biobanks' research results: What do (potential) participants want? American Journal of Medical Genetics Part A 152A (10):2482-2492. doi:10.1002/ajmg.a.33617

Morreim EH (2005) The clinical investigator as fiduciary: Discarding a misguided idea. Journal of Law, Medicine and Ethics 33 (3):586-599 
Murphy J, Scott J, Kaufman D, Geller G, LeRoy L, Hudson K (2008) Public Expectations for Return of Results from Large-Cohort Genetic Research. The American Journal of Bioethics 8 (11):36 $-43$

Naish J (2010) Ancestor-hunting holidays get a DNA boost. Times Online. http://www.timesonline.co.uk/tol/travel/holiday_type/history_and_travel/article7117218.ece. Accessed 20 April 2011

NHGRI Intramural Research Bioethics Core (2010) Points to Consider in the Transition Toward Whole-Genome Sequencing in Human Subjects Research. http://www.genome.gov/Pages/Research/Intramural/IRB/WESWGS_Points_to_Consider.pdf. Accessed 20 April 2011

OECD (2009) Organisation for Economic Co-operation and Development Guidelines for Human Biobanks and Genetic Research Databases (HBGRDs). http://www.oecd.org/dataoecd/41/47/44054609.pdf. Accessed 3 March 2011

PGP (2011) Personal Genome Project Consent Form. http://www.personalgenomes.org/consent/PGP_Consent_Approved_02222011.pdf. Accessed 20 April 2011

Pollack A (2008) Gene Testing Questioned by Regulators. The New York Times. http://www.nytimes.com/2008/06/26/business/26gene.html. Accessed 20 April 2011

Ravitsky V, Wilfond BS (2006) Disclosing Individual Genetic Results to Research Participants. The American Journal of Bioethics 6 (6):8 - 17

Robbers MLP (2008) Blinded by Science. Criminal Justice Policy Review 19 (1):84-102. doi: $10.1177 / 0887403407305982$

Rothstein MA (2006) Tiered Disclosure Options Promote the Autonomy and Well-Being of Research Subjects. The American Journal of Bioethics 6 (6):20 - 21

Samuel GN, Jordens CFC, Kerridge I (2010) Direct-to-consumer personal genome testing: ethical and regulatory issues that arise from wanting to 'know' your DNA. Internal Medicine Journal 40 (3):220-224. doi:10.1111/j.1445-5994.2010.02190.x

Santos CA, Yan G (2010) Genealogical Tourism: A Phenomenological Examination. Journal of Travel Research 49 (1):56-67. doi:10.1177/0047287509332308

Secretary's Advisory Committee on Genetics Health and Society (2010) Direct-to-Consumer Genetic Testing. http://oba.od.nih.gov/oba/sacghs/reports/SACGHS_DTC_Report_2010.pdf. Accessed 20 April 2011

Stolk R, Rosmalen J, Postma D, de Boer R, Navis G, Slaets J, Ormel J, Wolffenbuttel B (2008) Universal risk factors for multifactorial diseases. European Journal of Epidemiology 23 (1):67-74. doi:10.1007/s10654-007-9204-4

UK10K (2010) UK10K Ethical Governance Framework. http://www.uk10k.org/assets/EF_UK10K_v21.pdf. Accessed 4 March 2011

UK Biobank (2011) Test Results. http://www.ukbiobank.ac.uk/faqs/results.php. Accessed 7 March 2011

Venter JC, Adams MD, Myers EW, Li PW, Mural RJ, Sutton GG, Smith HO, et al (2001) The Sequence of the Human Genome. Science 291 (5507):1304-1351. doi:10.1126/science. 1058040

Wallace S, Lazor S, Knoppers BM (2009) Consent and population genomics: The creation of generic tools. IRB 31 (2):15-20

Weisman R (2011) Patients take on expanded role. Boston Globe. http://articles.boston.com/2011-0322/business/29352119_1_patient-advocacy-health-care-diagnoses-and-treatments. Accessed 23 March 2011

Wheeler DA, Srinivasan M, Egholm M, Shen Y, Chen L, McGuire A, He W, et al (2008) The complete genome of an individual by massively parallel DNA sequencing. Nature 452 (7189):872-876.

doi:http://www.nature.com/nature/journal/v452/n7189/suppinfo/nature06884_S1.html 